\title{
Intoxicação por Amorimia spp. em ruminantes
}

\author{
Poisoning by Amorimia spp. in ruminants
}

\author{
Amélia Lizziane Duarte ${ }^{\mathrm{I}}$ Rosane Maria Trindade Medeiros $^{\mathrm{I}^{*}}$ Franklin Riet-Correa $^{\mathrm{I}}$
}

\section{- REVISÃO BIBLIOGRÁFICA -}

\section{RESUMO}

No Brasil, um dos grupos mais importantes de plantas tóxicas é o das que causam morte súbita associada ao exercício. Integram esse grupo, plantas das famílias Rubiaceae, Bignoniaceae e Malpighiaceae. A nomenclatura de algumas plantas da família Malpighiaceae designadas anteriormente como Mascagnia foram reclassificadas dentro do gênero Amorimia. Dentre as espécies tóxicas de Amorimia no Brasil, encontramse Amorimia amazonica, Amorimia exotropica, Amorimia pubiflora, Amorimia rigida, Amorimia septentrionalis, Amorimia sp. (complexo Mascagnia rigida; Mascagnia aff. rigida) e uma planta identificada como Mascagnia sepium, que provavelmente se trata de Amorimia amazonica. Em todas essas espécies, foi determinado que o princípio ativo é o monofluoroacetato de sódio (MFA). Outra espécie tóxica, Amorimia concinna, causa morte súbita em bovinos na Colômbia, mas não tem sido estabelecido que contenha MFA. Atualmente, as únicas alternativas para o controle da intoxicação são a utilização de herbicidas, a remoção manual das plantas ou o uso de cercas para evitar que os animais tenham acesso às plantas. Pesquisas demonstraram a possibilidade de utilizar a técnica de aversão condicionada para evitar que os animais ingiram A. rigida. Foi demonstrado que caprinos aumentam consideravelmente a resistência à intoxicação mediante a ingestão de quantidades não tóxicas de A. septentrionalis ou por transfaunação de conteúdo ruminal de animais resistentes para animais susceptíveis. Bactérias que hidrolisam MFA foram isoladas do solo, de folhas de A. septentrionalis e Palicourea aeneofusca e do rúmen de caprinos, sugerindo que a intoxicação possa ser prevenida pela inoculação intra-ruminal dessas bactérias.

Palavras-chave: Amorimia spp., insuficiência cardíaca aguda, Mascagnia spp., monofluoroacetato de sódio, morte súbita, plantas tóxicas.

\section{ABSTRACT}

In Brazil, one of the most important groups of toxic plants is that which causes sudden death associated with exercise,

\begin{abstract}
which comprises plants of the Rubiaceae, Bignoniaceae, and Malpighiaceae families. The nomenclature of some plants of the Malpighiaceae family, previously identified as Mascagnia, was modified to Amorimia. Among the species of toxic Amorimia in Brazil there are Amorimia amazonica, Amorimia exotropica, Amorimia pubiflora, Amorimia rigida, Amorimia septentrionalis, Amorimia sp. (Mascagnia rigida complex; Mascagnia aff. rigida), and a plant identified as Mascagnia sepium, which is probably Amorimia amazonica. In these species the toxic compound is sodium monofluoroacetate (MFA). Another toxic species, Amorimia concinna, causes sudden death in cattle in Colombia, but it has not been established if it contains MFA. Currently the only alternatives for controlling the poisoning is the use of herbicides, manual removal of the plants, or the use of fences to prevent animals access. Research has demonstrated the possibility of using conditioned food aversion to avoid A. rigida ingestion. It has been demonstrated that goats greatly increased resistance to poisoning by ingestion of non-toxic amounts of A. septentrionalis or by transfaunation of rumen contents from resistant to susceptible goats. Bacteria that hydrolyze MFA were isolated from soil, from leaves of A. septentrionalis and Palicourea aeneofusca and from ruminal content of goats, suggesting that toxicity can be prevented by intra-ruminal inoculation of bacteria that hydrolyze MFA.
\end{abstract}

Key words: Amorimia spp., acute heart failure, Mascagnia spp., sodium monofluoroacetate, sudden death, toxic plants.

\section{INTRODUÇÃO}

Um dos mais importantes grupos de plantas tóxicas no Brasil é o das que causam morte súbita associada ao exercício, que tem como principal característica a manifestação de sinais clínicos, quando os animais são movimentados. Integram esse grupo plantas das famílias Rubiaceae, Bignoniaceae

IHospital Veterinário, Centro de Saúde e Tecnologia Rural (CSTR), Universidade Federal de Campina Grande (UFCG), 58700-000, Patos, PB, Brasil. E-mail: rmtmed@uol.com.br.*Autor para correspondência. 
e Malpighiaceae. No Brasil, há atualmente 13 plantas que causam esse quadro clínico: Palicourea marcgravii, Palicoureia aeneofusca, Palicourea juruana, Palicourea grandiflora, Tanaecium bilabiatum (anteriomente conhecida comoArrabidaea bilabiata), Fridericia (Arrabidaea) japurensis, Pseudocalymma elegans, Amorimia (Mascagnia) rigida, Amorimia (Mascagnia) pubiflora, Amorimia (Mascagnia) exotropica, Amorimia sp. (complexo M. rigida; M. aff. rigida) (TOKARNIA et al., 2012; LEE et al., 2012), Amorimia septentrionalis, e uma planta identificada como Mascagnia sepium, mas que provavelmente se trata de Amorimia (Mascagnia) amazonica (LEE et al., 2012). Amorimia spp. são lianas, arbustos ou semiarbustos com caules finos que possuem frutos (samaras) alados lateralmente, com 10 estames férteis e estigmas internas (ANDERSON, 2006). Diversas espécies de Mascagnia, incluindo todas as espécies tóxicas, foram reclassificadas como Amorimia. De acordo com ANDERSON (2006), as espécies de Amorimia distinguem-se das espécies de Mascagnia por possuir glândulas na superfície abaxial das folhas, pétalas pilosas abaxiais, brácteas glandulares e estiletes retos e eretos e pela morfologia das samaras.

A maioria dessas plantas contem monofluoroacetato se sódio (MFA) (OLIVEIRA, 1963; KREBS et al., 1994; CUNHA et al., 2012; LEE et al., 2012). Essa substância não foi pesquisada em $\boldsymbol{P}$. juruana, $\boldsymbol{P}$. grandiflora, $\boldsymbol{P}$. elegans e $\boldsymbol{F}$. japurensis, no entanto, a semelhança do quadro clínico-patológico entre todas as intoxicações por ingestão dessas plantas sugere que o princípio ativo dessas espécies também seja o MFA. A concentração de MFA difere significativamente entre essas espécies que causam morte súbita associada ao exercício, o que pode explicar as variações na incidência de intoxicações e as diferentes quantidades de material vegetal necessárias para causar a morte (LEE et al., 2012).

No Brasil, são descritas sete espécies de Amorimia, dessas, cinco são comprovadamente tóxicas (A. rigida, A. septentrionalis, A. pubiflora, A. exotropica e A. amazonica) (TOKARNIA et al., 1961; TOKARNIA \& DOBEREINER, 1973; GAVA et al., 1998; VASCONCELOS et al., 2008a; LEE et al., 2012). Duas espécies ainda não foram relatadas como tóxicas (A. maritima e A. velutina) (LEE et al., 2012). Este trabalho objetiva realizar uma revisão das intoxicações causadas pelas diferentes espécies tóxicas de Amorimia, no Brasil e em outros países da América Latina.
Epidemiologia e toxicidade

Amorimia rigida (A. Juss.) W.R. Anderson (anteriormente Mascagnia rigida)

A A. rigida é a planta tóxica mais conhecida, difundida e importante para a Região Nordeste do Brasil. Ocorre também no Nordeste de Minas Gerais e Norte do Espírito Santo (TOKARNIA et al., 1990, 2012). Exemplares de A. rigida coletados na Paraíba (VASCONCELOS et al., 2008a) foram reclassificados como $\boldsymbol{A}$. Septentrionalis, de acordo com ANDERSON (2006), portanto, existe a possibilidade de que $\boldsymbol{A}$. septentrionalis ocorra em outros Estados do Nordeste e tenha sido identificada equivocadamente como A. rigida. A reclassificação das espécies de Amorimia que causam intoxicações na Região Nordeste e Norte de Minas Gerais é importante para determinar a distribuição geográfica de A. rigida e A. septentrionalis.

Os principais nomes populares pelos quais A. rigida é conhecida são tingui e timbó. Na Bahia, é conhecida ainda pelos nomes populares quebrabucho e pela-bucho. Nos vales dos rios Jequitinhonha e Mucuri (Minas Gerais), é conhecida pelos termos salsa-rosa e rama-amarela e, no vale do rio Doce (Minas Gerais e Espirito Santo), pelos nomes sumabranca e suma-roxa (TOKARNIA et al., 2012). A variação na toxicidade da planta é relatada e a ocorrência de intoxicação varia entre áreas e fazendas na mesma região (TOKARNIA et al., 2012).

A intoxicação por A. rigida ocorre principalmente no início do período chuvoso, quando ela está brotando e as outras plantas ainda não cresceram, pois a $\boldsymbol{A}$. rigida apresenta um sistema radicular muito desenvolvido. A brotação também pode ocorrer após queimadas, também considerado como o período de maior número de casos de intoxicações (BORBOLETA, 2010; TOKARNIA et al., 2012). Sob condições naturais, a intoxicação por A. rigida ocorre principalmente na espécie bovina (TOKARNIA et al., 1961, 1994; MEDEIROS et al., 2002; SILVA et al., 2006; VASCONCELOS et al., 2008b); é menos frequente em caprinos (OLIVEIRA et al., 1978) e ovinos (PACÍFICO DA SILVA et al., 2008; LAGO et al., 2009). Experimentalmente, a intoxicação foi reproduzida nessas três espécies (TOKARNIA et al., 1961, 1994; SANTOS 1975; PARAGUASSU, 1983; PACÍFICO DA SILVA et al., 2008; VASCONCELOS et al., 2008a; LAGO et al., 2009).

Os animais se intoxicam ao ingerirem as folhas. Apesar de numerosos experimentos realizados, não se determinou a dose letal para bovinos e caprinos, uma vez que os resultados apresentam uma ampla variação (TOKARNIA et al., 2012), que 
possivelmente está diretamente relacionada com a quantidade de MFA na planta (LEE et al., 2012). A concentração média de MFA em amostras de $\boldsymbol{A}$. rigida presentes no Herbário da Universidade de Michigan foi de 0,002\% (LEE et al., 2012).

\section{Amorimia septentrionalis W.R. Anderson}

A A. septentrionalis, também conhecida como tingui, ocorre na região Nordeste do Brasil, especialmente nos Estados do Ceará, Paraíba e Pernambuco (MAMEDE, 2010). A intoxicação por essa planta foi descrita em ovinos e caprinos no estado da Paraíba, onde inicialmente havia sido classifica como $\boldsymbol{A}$. rigida (VASCONCELOS et al., 2008a). A doença ocorre principalmente no início do período chuvoso, quando a planta brota antes que outras forrageiras ou após o final desse período, quando algumas forrageiras secam e a $\boldsymbol{A}$. septentrionalis permanece verde (VASCONCELOS et al., 2008a). Na reprodução experimental em caprinos e ovinos, doses únicas de 10 e $20 \mathrm{~g} \mathrm{~kg}^{-1}$ de peso corporal foram letais. Já animais que receberam a dose de $5 \mathrm{~g} \mathrm{~kg}^{-1}$ apresentaram sinais discretos e se recuperaram da intoxicação (VASCONCELOS et al., 2008a). A concentração de MFA em amostras de A. septentrionalis foi de $0,002 \pm 0,0009 \%$ em folhas, $0,001 \pm 0,0003 \%$ em caules, 0,008 $\pm 0,004$ em flores e $0,006 \pm 0,002 \%$ em sementes (LEE et al., 2012).

Amorimia pubiflora, (A. Juss.) W.R. Anderson (anteriormente Mascagnia pubiflora).

A A. pubiflora é uma das plantas tóxicas mais importantes da região Centro-Oeste e áreas vizinhas da Região Sudeste (TOKARNIA \& DOBEREINER, 1973). Ela também ocorre nos estados da Bahia, Minas Gerais, São Paulo e Rio de Janeiro (MAMEDE, 2010), no entanto, a intoxicação não tem sido diagnosticada nesses Estados.

A A. pubiflora tem como nomes populares corona e cipó-prata. Há duas formas da planta, uma em que as folhas são glabras, isto é, desprovidas de pelos, e outra que são pilosas, o que dá aspecto prateado à brotação, aplicando, para esta última forma, o termo popular cipó-prata (TOKARNIA \& DOBEREINER, 1973; TOKARNIA et al., 2012).

Sob condições naturais e experimentais, a única espécie em que se constatou a intoxicação por $\boldsymbol{A}$. pubiflora foi a bovina (TOKARNIA \& DOBEREINER, 1973; LEMOS et al., 2011). No Mato Grosso do Sul, $\boldsymbol{A}$. pubiflora foi responsável por dez surtos de morte súbita durante o período de janeiro, março, maio, novembro e dezembro (período chuvoso). A morbidade variou de $1 \%$ a $3,5 \%$ e a taxa de letalidade foi de $100 \%$. Em oito desses focos, a movimentação dos animais foi o fator desencadeante para a observação de sinais clínicos (LEMOS et al., 2011).

As duas formas de A. pubiflora, glabra e pilosa, têm a mesma toxicidade para bovinos. Há, porém, grande variação na toxidez das folhas de acordo com a época do ano (TOKARNIA \& DOBEREINER, 1973). Enquanto em agosto/ setembro de 1971, na época da seca, com a $\boldsymbol{A}$. pubiflora em brotação, floração e frutificação, a dose letal das folhas frescas foi de $5 \mathrm{~g} \mathrm{~kg}^{-1}$, em abril/maio do mesmo ano, no final da época de chuva, com as folhas maduras, ela situou-se em torno de $20 \mathrm{~g} \mathrm{~kg}^{-1}$ (TOKARNIA \& DOBEREINER, 1973). O MFA foi encontrado em amostras de A. pubiflora mantidas no Herbário da Universidade de Michigan, em concentrações de 0,006\% (LEE et al., 2012).

\section{Amorimia sp. (complexo Mascagnia rigida; Mascagnia aff. rigida) \\ A Amorimia sp. (complexo $\boldsymbol{M}$. rigida; $\boldsymbol{M}$.} aff. rigida) é encontrada no Brasil, na região norte do Espírito Santo (TOKARNIA et al., 1985a) e há indícios de que ocorre também na Bahia (TOKARNIA et al., 2012). Causa prejuízos elevados nos locais onde ocorre e não possui nome popular nessas regiões (TOKARNIA et al., 1985a). É uma planta tóxica de menor importância, devido à sua distribuição limitada. O seu habitat são os lugares de relevo mais baixos dos pastos (TOKARNIA et al., 2012).

Sob condições naturais, a intoxicação por Amorimia sp. (complexo M. rigida; M. aff. rigida) ocorre em qualquer época do ano. Aparentemente, a planta tem boa palatabilidade e, nos pastos onde ela vegeta, sempre são observadas mortes em bovinos (TOKARNIA et al., 2012). Experimentalmente, a intoxicação foi reproduzida com folhas frescas ou dessecadas (TOKARNIA et al., 1985b) e foi verificado que há diferença na toxidez de acordo com a procedência, com a dose letal variando entre $0,625 \mathrm{~g} \mathrm{~kg}^{-1}$ e $2,5 \mathrm{~g} \mathrm{~kg}^{-1}$. Dados semelhantes foram obtidos em experimentos em coelhos (TOKARNIA et al., 2012). O MFA foi encontrado em amostras dessa planta cultivadas no Estado do Rio de Janeiro na concentração de 0,005\% (LEE et al., 2012).

Amorimia exotropica (Griseb.) W.R. Anderson (anteriormente Mascagnia exotropica)

A A. exotropica foi identificada na região Sul do Brasil, Estados do Paraná, Santa Catarina e Rio Grande do Sul (GAVA et al., 1998). Não possui nome popular e a importância da intoxicação é muitas vezes subestimada, devido ao desconhecimento da planta 
pelos produtores e técnicos dessas regiões (PAVARINI et al., 2011). Sob condições naturais, a intoxicação por A. exotropica tem sido constatada principalmente em bovinos (GAVA et al., 1998; COLODEL et al., 1999; PAVARINI et al., 2011), mas também em bubalinos (COLODEL et al., 1999), caprinos e ovinos (BANDARRA et al., 2005). Experimentalmente, a intoxicação foi reproduzida em bovinos (GAVA et al., 1998) e caprinos (BANDARRA et al., 2005).

A A. exotropica geralmente encontra-se em ambiente sombreado, no interior e beira de matas e capões, principalmente, em encostas de morros. Os ramos de $\boldsymbol{A}$. exotropica, em sua maioria, ficam sobre as copas das árvores, fora do alcance do gado, que tem acesso apenas aos brotos das plantas, os quais, muitas vezes, predominam entre a vegetação rasteira no interior das matas (PAVARINI et al., 2011). Proprietários relataram morte repentina de animais, com perdas de até $40 \%$ dos seus rebanhos, em um ano (GAVA et al., 1998). De acordo com PAVARINI et al. (2011), as intoxicações ocorrem durante todo o ano; entretanto, a maior concentração de casos, entre os meses de maio e agosto, provavelmente pode estar relacionada à carência de alimento comum nesta época do ano no Sul do Brasil, fazendo com que os bovinos possam invadir áreas de matas ou capões à procura de alimento ou devido à procura de abrigo das chuvas e ventos frios, que também se concentram nessa época.

Doses únicas de 7,5-10g $\mathrm{kg}^{-1}$ de folhas frescas de $\boldsymbol{A}$. exotropica causaram intoxicação e morte dos animais e doses únicas de $5 \mathrm{~g} \mathrm{~kg}^{-1}$ das folhas frescas causaram intoxicação, sem morte (GAVA et al., 1998). O MFA foi encontrado em amostras de A. exotropica mantidas no Herbário da Universidade de Michigan na concentração de 0,02\% (LEE et al., 2012).

Amorimia amazonica (Nied.) W.R. Anderson (anteriormente Mascagnia amazonica)

SCHONS et al. (2011) relataram morte súbita associada ao exercício em bovinos e ovinos no Estado de Rondônia, região Norte do Brasil, causados pela ingestão de uma planta identificada como Mascagnia sepium. No entanto, não há relatos dessa espécie na região Norte do Brasil (LEE et al., 2012), sendo encontrada nas regiões Nordeste (Piauí, Pernambuco e Bahia), Centro-Oeste (Mato Grosso e Goiás) e Sudeste (Minas Gerais, Espírito Santo e São Paulo) (MAMEDE, 2010). A partir de uma foto da suposta planta, esta foi identificada como sendo provavelmente A. Amazonica, o que, associado à localização geográfica dos surtos, sugere que tenham sido causados por A. amazonica (LEE et al., 2012).
No Brasil, a A. amazonica é encontrada nas regiões Norte (Amazonas e Acre) e CentroOeste (Mato Grosso). A planta é encontrada também na Bolívia e Peru (MAMEDE, 2010); no entanto, surtos de intoxicação não têm sido relatados nesses países. O MFA foi encontrado em amostras mantidas no Herbário da Universidade de Michigan, em concentração inferior a 0,0007\% (LEE et al., 2012).

Mascagnia elegans [atualmente Mascagnia divaricata (Kunth) Nied]

A Mascagnia divaricata foi descrita como tóxica para bovinos no sertão Pernambucano (TOKARNIA et al., 1990). No entanto, não são encontrados exemplares de $\boldsymbol{M}$. divaricata em nenhum herbário da região semiárida do Brasil e acredita-se que a planta identificada como $\boldsymbol{M}$. divaricata tratavase da A. septentrionalis (LEE et al., 2012). A $\boldsymbol{M}$. divaricata é encontrada nas regiões Norte, CentroOeste, Sudeste e Sul, mas não na região Nordeste (MAMEDE, 2010). Exemplares de M. divaricata mantidas no Herbário da Universidade de Michigan foram utilizados para determinação de MFA, com resultados negativos (LEE et al., 2012).

Amorimia concinna (C. V. Morton) W. R. Anderson (anteriormente Mascagnia concinna)

Segundo DIAZ et al. (2011), a A. concinna é um arbusto nativo encontrado no vale de Magdalena, na Colômbia, conhecida pelos nomes populares de mindaca, mataganado e cansaviejo. É tóxica para a espécie bovina e causa morte súbita associada ao exercício (DIAZ et al., 2011), quadro clínico conhecido na Colômbia como caída del ganado (TRHEEBILCOCK et al., 1978).

Essa planta contem glicosídeos cianogênicos e também é conhecida por acumular concentrações tóxicas de nitrato. As concentrações de nitrato variam entre 5,30-29,20 e 1,55-10,763ppm na matéria seca (TORRES, 1984) e fresca (TRHEEBILCOCK et al., 1978), respectivamente, e os teores de ácido cianídrico (HCN) são maiores que 40mg de HCN em 100g de planta (TORRES, 1984). Em estudo realizado por GOMEZ (1975), verificouse que menos de $2 \mathrm{~g}$ de folhas frescas por $\mathrm{kg}$ de peso corporal foram letais para bovinos durante a época seca e que esta espécie acumula maiores quantidades de glicosídeos cianogênicos durante essa época se comparado com a época chuvosa. Apesar de a planta conter HCN e nitratos, dificilmente essas substâncias, que tem que ser ingeridas em grandes quantidades, sejam responsáveis pela intoxicação. É provável que, como em outras espécies de Amorimia, a toxicidade da $A$. concinna é causada também por MFA. 
Amorimia camporum W.R. Anderson

A A. camporum é uma nova espécie descrita por ANDERSON (2006), em amostras procedentes do Peru, previamente identificadas como Amorimia (Mascagnia) pubiflora. Ocupa áreas tropicais sazonalmente secas (LEÓN, 2006). Apesar de a A. camporum conter MFA (LEE et al., 2012), não foram encontradas descrições de intoxicações por essa espécie no Peru. A. camporum não possui nome popular (LEÓN, 2006). O MFA foi identificado em amostras de $\boldsymbol{A}$. camporum mantidas no Herbário da Universidade de Michigan, em concentração inferior a 0,0007\% (LEE et al., 2012).

\section{Sinais clínicos}

O MFA inibe competitivamente a citrato aconitase, resultando em bloqueio do ciclo de Krebs e redução da produção de ATP (PETERS, 1952), causando insuficiência cardíaca. De maneira geral, os sinais clínicos são precipitados quando os animais são expostos ao exercício físico. Em bovinos, esses sinais são caracterizados por instabilidade, tremores musculares, movimentos de pedalagem, opistótono, vocalização, respiração irregular, taquicardia com arritmia e veias jugulares ingurgitadas e pulsantes. Os animais têm dificuldade em se levantar, não conseguem permanecer em pé, caem em decúbito esterno-abdominal, ou logo em decúbito lateral. Alguns animais podem se recuperar se não forem forçados a andar e outros morrem em minutos ou horas (GAVA et al., 1998; RIET-CORREA et al., 2006; TOKARNIA et al., 2012). Em um surto de intoxicação por $A$. rigida, $50 \%$ dos animais que adoeceram se recuperaram (MEDEIROS et al., 2002). É provável que essa relativamente baixa letalidade seja devida às baixas concentrações de MFA em Amorimia spp. (0,0007\%-0,02\%). Na intoxicação por Palicourea spp., que contém quantidades maiores de MFA (0,21-0,24\% para $\boldsymbol{P}$. marcgravii e 0,09 em P. aeneofusca) (LEE et al., 2012), geralmente, os animais não se recuperam e podem ser encontrados mortos sem apresentarem qualquer manifestação clínica (TOKARNIA et al., 2012).

Caprinos e ovinos apresentam ingurgitamento das veias jugulares, relutância em se movimentar, incoordenação e marcha instável, decúbito esternal, dispneia, insuficiência respiratória, depressão, tremores musculares e quedas (PACÍFICO DA SILVA et al., 2008; VASCONCELOS et al 2008a). Caprinos que recebem diariamente doses não tóxicas de $\boldsymbol{A}$. septentrionalis apresentam sinais clínicos, mas, geralmente, recuperam-se, caso a administração é suspensa imediatamente após a observação de alguma alteração clínica (DUARTE et al., 2012). De acordo com TOKARNIA et al. (2012), o período de tempo para eliminação do princípio tóxico do organismo animal é de 8 a 14 dias.

\section{Achados de necropsia e histológicos}

Geralmente, não há lesões macroscópicas de significância, no entanto, lesões típicas de insuficiência cardíaca aguda, tais como mucosas levemente cianóticas, petéquias e equimoses no epicárdio, ingurgitamento jugular, hidropericárdio, coágulos no interior do ventrículo esquerdo, edema pulmonar e congestão hepática e do trato gastrintestinal podem ser encontrados (TOKARNIA et al., 1961, 1994; PARAGUASSU, 1983; PACÍFICO DA SILVA et al., 2008; VASCONCELOS et al., 2008b; PAVARINI et al., 2011). O coração com aspecto globular e áreas esbranquiçadas no miocárdio também é característico (SOARES et al., 2012)

Histologicamente, no coração, observa-se necrose de coagulação no miocárdio, caracterizada por retração celular, aumento da eosinofilia do citoplasma com perda das estriações, vacúolos intracitoplasmáticos, vacúolos intranucleares com marginalização da cromatina e núcleos picnóticos e, ocasionalmente, em cariorrexia ou cariólise (PAVARINI et al., 2012). Há também edema intersticial e infiltrado inflamatório intersticial, predominantemente mononuclear (PAVARINI et al., 2011). Em alguns animais, ocorrem áreas multifocais e coalescentes de fibrose cardíaca (SCHONS et al., 2011; SOARES et al., 2012). Na microscopia eletrônica, no coração de coelhos intoxicados experimentalmente, observou-se severa tumefação de cardiomiócitos associada com tumefação das mitocôndrias, com deslocamento e ruptura das cristas mitocondriais e das bandas da miofibras e deposição de glicogênio no citoplasma (SOARES et al., 2012). Nos rins, em aproximadamente 50\% dos animais mortos pela intoxicação, observa-se degeneração hidrópico vacuolar e necrose nos túbulos uriníferos contornados distais (TOKARNIA et al., 1961, 1985ab; VASCONCELOS et al., 2008ab; PAVARINI et al., 2011; TOKARNIA et al., 2012). Essa lesão renal é semelhante à encontrada em outras plantas que contêm MFA e na intoxicação por MFA (NOGUEIRA et al., 2010)

Diagnóstico e medidas de prevenção e/ou controle

O histórico mencionando que os animais morrem ou adoecem ao serem movimentados e a presença de Amorimia spp. sugerem o diagnóstico de intoxicação. A lesão microscópica dos rins, quando 
presente, é de grande valor diagnóstico (TOKARNIA et al., 2012).

O controle da intoxicação é difícil. A remoção manual da planta é uma boa medida de controle para pequenas áreas, porém esse procedimento não é viável em áreas onde a planta está difundida. Amorimia spp. possui raiz persistente que predispõe a rebrota após remoção ou utilização de herbicidas. O uso de cercas para isolar as áreas com a planta é uma medida de controle usada em algumas fazendas (RIET-CORREA \& MEDEIROS, 2001). Em fazendas onde a intoxicação é frequente, os produtores costumam deixar os animais sem movimentação, em áreas em que não existem as plantas, por um período de 7 a 15 dias antes de transportá-los ou realizar procedimentos como vacinações ou vermifugações (RIET-CORREA et al., 2006).

Em ovinos (PACÍFICO DA SILVA et al., 2010) e caprinos (BARBOSA et al., 2008), foi induzida experimentalmente aversão alimentar condicionada, administrando-se cloreto de lítio após a ingestão de A. rigida, no entanto, não foi estabelecida a duração da aversão nem as possibilidades do emprego dessa técnica em fazendas comerciais para evitar a ingestão de $A$. rigida.

Na Paraíba, foi comprovado que a administração de doses não tóxicas repetidas de folhas de $\boldsymbol{A}$. septentrionalis induz resistência à intoxicação por essa planta e que essa resistência pode ser transmitida de animais resistentes para animais susceptíveis pela transfaunação de líquido ruminal (DUARTE, 2012). Bactérias aeróbicas que degradam o MFA foram isoladas de solo e folhas de A. septentrionalis (CAMBOIM et al., 2012a) e do rúmen de caprinos criados em áreas onde não ocorrem plantas que contêm MFA (CAMBOIM et al., 2012b). Esses achados sugerem que a intoxicação poderia ser controlada pela administração intra-ruminal de bactérias que degradam MFA. O isolamento dessas bactérias de animais criados em áreas onde não ocorrem plantas que contêm MFA sugere que elas ocorram naturalmente no rúmen dos animais, e que a administração de subdoses de $\boldsymbol{A}$. septentrionalis pode servir como substrato, favorecendo a multiplicação destas e aumentando a resistência dos animais à intoxicação (CAMBOIM et al., 2012b).

\section{CONCLUSÃO}

Considerando que ocorreram mudanças na identificação das diferentes espécies tóxicas de Amorimia encontradas no Brasil, é necessário realizar coletas sistemáticas de exemplares de plantas encontradas nos locais onde ocorrem os surtos, para determinar a distribuição geográfica das espécies.

Uma vez comprovado que todas as espécies tóxicas de Amorimia contêm MFA, e considerando as dificuldades em controlar a planta pelos métodos tradicionais, é necessário continuar trabalhos de pesquisa que comprovem a hipótese de que a intoxicação pode ser evitada mediante a inoculação intra-ruminal de bactérias que hidrolisam o monofluoroacetato.

\section{REFERÊNCIAS}

ANDERSON, W.R. Eight segregates from the neotropical genus Mascagnia (Malpighiaceae). Novon, v.16, p.168-204, 2006. Disponível em: <http://cncflora.jbrj.gov.br/plataforma2/arquivos/ biblio/50b8ceeec92bd_Mascagnia\%20Anderson,\%202006.pdf>. Acesso em: 11 jun. 2011 doi: http://dx.doi.org/10.3417/10553177(2006)16[168:ESFTNG]2.0.CO;2.

BANDARRA, P.M. et al. Intoxicações em ruminantes por Mascagnia sp. no Rio Grande do Sul diagnosticados no Setor de Patologia Veterinária, Porto Alegre, RS. In: SALÃO DE INICIAÇÃO CIENTÍfICA, 17., 2005, Porto Alegre, RS. Anais.. Porto Alegre: UFRGS, 2005. V.1, p.225.

BARBOSA, R.R. et al. Development of conditioned taste aversion to Mascagnia rigida in goats. Pesquisa Veterinária Brasileira. v.28, n.12, p.571-574, 2008. Disponível em: <http://dx.doi.org/10.1590/ S0100-736X2008001200001>. Acesso em: 11 jun. 2011.

BORBOLETA, L.R. Intoxicação experimental com extratos de Mascagnia rigida (A. Juss.) Griseb. (Malpighiaceae) em coelhos (Oryctolagus cuniculus): estudos clínico, laboratorial e anatomopatológico. 2010. 143f. Dissertação (Mestrado em ciência animal) - Curso de Pós-graduação em Ciência Animal, Universidade Federal de Minas Gerais, MG.

CAMBOIM E.K.A. et al. Defluorination of sodium fluoroacetate by bacteria from soil and plants in Brazil. Scientific World Journal, Article ID 149893, 5 pages, 2012a. Disponível em: <http://www.tswj.com/2012/149893/>. Acesso em: 12 fev. 2012. doi:10.1100/2012/149893.

CAMBOIM E.K.A. et al. Isolation of sodium fluoroacetate degrading bacteria from caprine rumen in Brazil. Scientific World Journal, Article ID 178254, 6 pages, 2012b. Disponível em: <http://www.tswj.com/2012/178254/>. Acesso em: 10 jul. 2012b. doi:10.1100/2012/178254.

COLODEL, E.M. et al. Intoxicação por Mascagnia sp. (Malpighiaceae) em bovinos no Rio Grande do Sul, Pirassununga, SP. In: ENAPAVE, 9., 1999, Belo Horizonte, MG. Anais... Belo Horizonte: UFMG, 1999. V.1, p.144.

CUNHA, L.C. et al. Isolation and characterization of sodium 2-fluoroacetate from Mascagnia rigida using chromatography and infrared spectroscopy. Toxicon, v.60, p.329-332, 2012. Disponível em: <http://www.ncbi.nlm.nih.gov/pubmed/22561423>. Acesso em: 12 jul. 2012. doi: 10.1016/j.toxicon.2012.04.346.

DIAZ, G.J. et al. Toxic plants affecting grazing cattle in Colombia. In: RIET-CORREA, F. et al. Poisoning by plants, mycotoxins 
and related toxins. Cambridge, MA: CAB International, 2011. Cap.5, p.50-59

DUARTE, A.L.L. Intoxicações por Amorimia spp. e Callaeum psilophyllum em ruminantes. 2012. 68f. Tese (Doutorado em Medicina Veterinária)-Programa de Pós-graduação em Medicina Veterinária, Universidade Federal de Campina Grande, PB.

GAVA, A. et al. Morte súbita em bovinos causada pela ingestão de Mascagnia sp. (Malpighiaaceae), no Estado de Santa Catarina. Pesquisa Veterinária Brasileira. v.18, n.1, p.16-20, 1998 Disponível em: <http://www.scielo.br/pdf/\%0D/pvb/v18n1/0902. pdf>. Acesso em: 10 jun. 2012. htp://dx.doi.org/10.1590/S0100736X1998000100003.

GOMEZ, W.B. Mascagnia concinna (Morton), a plant poisonous to cattle. Revista do Instituto Colombiano Agropecuário, v.10 n.4, p.513-514, 1975

KREBS, H.C. et al. Qualitative and quantitative determination of fluoroacetic acid in Arrabidea bilabiata and Palicourea marcgravii by F-NMR spectroscopy. Toxicon, v.32, n.8, p.909913, 1994. Disponível em: <http://www.sciencedirect.com/ science/article/pii/0041010194903697>. Acesso em: 11 jan. 2011. doi: 10.1016/0041-0101(94)90369-7.

LAGO, E.P. et al. Perfis eletrocardiográfico e ecodopplercardiográfico de ovinos após ingestão da suspensão aquosa de Mascagnia rigida Griseb. (Malpighiaceae). Arquivo Brasileiro de Medicina Veterinária e Zootecnia, v.61, n.4, p.853-862, 2009. Disponível em: <http://www.scielo.br/scielo. php?script=sci_arttext\&pid=S0102-09352009000400012>. Acesso em: 10 jun. 2012. http://dx.doi.org/10.1590/S010209352009000400012

LEE, S.T. et al. Detection of monofluoroacetate in Palicourea and Amorimia species. Toxicon, v.60, n.5, p.791-796, 2012. Disponível em: <http://www.ncbi.nlm.nih.gov/pubmed/22699106>. Aceso em: 01 jun. 2012. doi: 10.1016/j.toxicon.2012.05.029.

LEMOS, R.A.A. et al. Plant poisonings in Mato Grosso do Sul. In: RIET-CORREA, F. et al. Poisoning by plants, mycotoxins and related toxins. Cambridge, MA: CAB International, 2011. Cap.11, p.68-72.

LEÓN, B. Malpighiaceae endémicas del Perú. Revista Peruana de Biología. v.13, n.2, p.409-412, 2006. Disponível em: <http:// sisbib.unmsm.edu.pe/bvrevistas/biologia/v13n2/pdf/a73.pdf > . Acesso em: 12 set. 2012.

MAMEDE, M.C.H. Amorimia in Lista de Espécies da Flora do Brasil. Jardim Botânico do Rio de Janeiro, 2010. Acesso em 12 set. 2012. Online. Disponível em: <http://floradobrasil.jbrj.gov. br/2010/FB101439>.

MEDEIROS, R.M.T. et al. Sudden bovine death from Mascagnia rigida in Northeastern Brazil. Veterinary and Human Toxicology, v.44, n.5, p.286-288, 2002.

NOGUEIRA, V.A. et al. Intoxicação experimental por monofluoroacetato de sódio em bovinos: aspectos clínicos e patológicos. Pesquisa Veterinária Brasileira, v.30, n.7, p.533-540, 2010. Disponível em: <http:/www.scielo.br/scielo. php?pid=S0100-736X2010000700004\&script=sci_arttext $>$. Acesso em: 12 jun. 2012. http://dx.doi.org/10.1590/S0100736X2010000700004.
OLIVEIRA, M.M. Chromatographic isolation of monofluoroacetic acid from Palicourea marcgravii, St. Hill. Experientia, v.19, n.11, p.586-587, 1963.

OLIVEIRA, A.C. et al. Intoxicação por um "tingui” (Mascagnia rigida Griseb.) em caprinos na Bahia. In: CONGRESSO BRASILEIRO DE MEDICINA VETERINÁRIA, 16., 1978, Salvador, BA. Anais... Bahia: CFMV, 1978. V.1, p.172.

PACÍFICO DA SILVA, I. et al. Intoxicação natural pelas folhas de Mascagnia rigida (Malpighiaceae) em ovinos. Arquivos do Instituto Biologico, v.75, n.2, p.229-233, 2008.

PACÍFICO DA SILVA, I. et al. Conditioning taste aversion to Mascagnia rigida (Malpighiaceae) in sheep. Research in Veterinary Science, v.88, p.239-241, 2010. Disponível em: <http://dx.doi.org/10.1016/j.rvsc.2009.08.012>. Acesso em: 29 abr. 2010. doi:10.1016/j.rvsc.2009.08.012

PARAGUASSU, A.A. Intoxicação experimental por Mascagnia rigida Grisebach (Malpighiaceae) em caprinos no Nordeste do Brasil. 1983. 65f. Dissertação (Mestrado em Medicina Veterinária) - Curso de Pós-graduação em Ciências Veterinárias, Universidade Federal Rural do Rio de Janeiro, RJ.

PAVARINI, S.P. et al. Mortes súbitas em bovinos causadas por Amorimia exotropica (Malpighiaceae) no Rio Grande do Sul. Pesquisa Veterinária Brasileira, v.31, n.4, p.291-296, 2011. Disponível em: <http://www.scielo.br/pdf/pvb/v31n4/a04v31n4. pdf $>$. Acesso em: 10 jun. 2012. http://dx.doi.org/10.1590/S0100736X2011000400004.

PAVARINI, S.P. et al. Decreased expression of cardiac troponin $\mathrm{C}$ is associated with cardiac lesions in Amorimia exotropica poisoned cattle. Pesquisa Veterinária Brasileira, v.32, n.10, p.1005-1008, 2012. Disponível em: <http://www.scielo.br/scielo. php?pid=S0100-736X2012001000010\&script $=$ sci_arttext $>$. Acesso em: 12 jun. 2012. http://dx.doi.org/10.1590/S0100736X2012001000010

PETERS, R.A. Lethal synthesis. Proceedings of the Royal Society of London B Biological Sciences, v.139, n.895, p.143170, 1952

RIET-CORREA, F; MEDEIROS, R.M.T. Intoxicação por plantas em ruminantes no Brasil e no Uruguai: importância econômica, controle e riscos para a saúde pública. Pesquisa Veterinária Brasileira, v.21, n.1, p.38-42, 2001. Disponível em: <http:// www.scielo.br/scielo.php?script=sci_arttext\&pid=S0100736X2010000100003>. Acesso em: 15 jun 2010. http://dx.doi. org/10.1590/S0100-736X2001000100008

RIET-CORREA, F. et al. Plantas tóxicas da Paraíba. Patos: CSTR/UFCG, SEBRAE/PB, 2006. 58p.

SANTOS, H.L. Aspectos clínicos, laboratoriais e anatomohistopatológicos na intoxicação experimental de bovinos pela Mascagnia rigida. 1975. 36f. Dissertação (Mestrado em Medicina Veterinária) - Curso de Pós-graduação em Medicina Veterinária, Universidade Federal de Minas Gerais, MG.

SCHONS, S. et al. Poisoning by Amorimia (Mascagnia) sepium in sheep in northern Brazil. Toxicon, v.57, p.781-786, 2011. Disponível em: <http://dx.doi.org/10.1016/j.toxicon.2011.02.012>. Acesso em: 11 abr. 2011. doi:10.1016/j.toxicon.2011.02.012. 
SILVA, D.M. et al. Plantas tóxicas para ruminantes e eqüídeos no Seridó Ocidental e Oriental do Rio Grande do Norte. Pesquisa Veterinária Brasileira, v.26, n.4, p.223-236, 2006.

SOARES, M.P. et al. Amorimia exotropica poisoning as a presumptive cause of myocardial fibrosis in cattle. Journal of Veterinary Diagnostic Investigation, v.23, n.6, p.1223-1229, 2011. Disponível em: <http://vdi.sagepub.com/content/23/6/1226.full. pdf $>$. Acesso em: 12 dez. 2012. doi: 10.1177/1040638711425586.

TOKARNIA, C.H. et al. Intoxicação por um “tingui” (Mascagnia rigida Griseb.) em bovinos no Nordeste do Brasil. Arquivos do Instituto Biológico Animal, v.4, p.203-205, 1961.

TOKARNIA, C.H.; DOBEREINER, J. Intoxicação por Mascagnia pubiflora em bovinos no Estado de Mato Grosso. Pesquisa Agropecuária Brasileira, v.8, p.61-68, 1973.

TOKARNIA, C.H. et al. Intoxicação por Mascagnia aff. rigida (Malpighiaceae) em bovinos no norte do Estado do Espírito Santo. Pesquisa Veterinária Brasileira, v.5, n.3, p.77-91, 1985a.

TOKARNIA, C.H et al. Intoxicação experimental por Mascagnia aff. rigida (Malpighiaceae) em coelhos. Pesquisa Veterinária Brasileira, v.5, n.4, p.121-128, 1985b.

TOKARNIA, C.H. et al. Poisonous plants affecting heart function of cattle in Brazil. Pesquisa Veterinária Brasileira, v.10, p.1-10, 1990.
TOKARNIA, C.H. et al. Aspectos clínicopatológicos complementares da intoxicação por algumas plantas tóxicas brasileiras. Pesquisa Veterinária Brasileira, v.14, n.4, p.111-122, 1994.

TOKARNIA, C.H. et al. Plantas tóxicas do Brasil para animais de produção. 2.ed. Rio de Janeiro: Helianthus, 2012. 566p.

TORRES, J.E. Plantas tóxicas para el ganado. Carta Ganadera, v.21, n.4, p.14-19, 1984.

TRHEEBILCOCK, E. et al. Síndrome caída del ganado contribuición a su estúdio. Revista do Instituto Colombiano de Agricultura, v.13, p.119-125, 1978.

VASCONCELOS, J.S. et al. Intoxicação por Mascagnia rigida (Malpighiaceae) em ovinos e caprinos. Pesquisa Veterinária Brasileira, v.28, n.10, p.521-526, 2008a. Disponível em: <http://www.scielo.br/pdf/pvb/v28n10/v28n10a13.pdf >. Acesso em: 03 fev. 2010. http://dx.doi.org/10.1590/S0100736X2008001000013.

VASCONCELOS, J.S. et al. Mortes súbitas em bovinos causadas por Palicourea aeneofusca (Rubiaceae) e Mascagnia rigida (Malpighiaceae) na Zona da Mata Paraibana. Pesquisa Veterinária Brasileira, v.28, n.10, p.457-460, 2008b. Disponível em: <http:// www.scielo.br/pdf/pvb/v28n10/v28n10a03.pdf>. Acesso em: 04 fev. 2010. http://dx.doi.org/10.1590/S0100-736X2008001000003. 